Egypt. J. of Appl. Sci., 35 (11) 2020

\title{
THE IMPACT OF VITAMIN D ON THE ENDOTHELIUM OF RHEUMATOID ARTHRITIS PATIENTS
}

\author{
Mashael F. Alotaibi ${ }^{1}$; Sawsan O. Khoja ${ }^{1}$; Wesam A. Alhejily ${ }^{2}$; \\ Sami M. Bahlas ${ }^{3}$; Alia M. Aldahlawi ${ }^{4,5}$;
}

Mahmoud E . Gadalla ${ }^{6}$ and Mohamed F. Elshal ${ }^{1,7}$

${ }^{1}$ Department of Biochemistry, Faculty of Science, King Abdulaziz University, Jeddah, Saudi Arabia.

${ }^{2}$ Cardiovascular medicine and interventional Cardiology, Faculty of medicine, King Abdulaziz University, Jeddah, Saudi Arabia.

${ }^{3}$ Department of Internal Medicine, College of Medicine, King Abdulaziz University, Jeddah, Saudi Arabia.

${ }^{4}$ Department of Biological Sciences, Faculty of Science, King Abdulaziz University, Jeddah, Saudi Arabia.

${ }^{5}$ Immunology Unit, King Fahd Medical Research Center, King Abdulaziz University, Jeddah, Saudi Arabia.

${ }^{6}$ Department of Molecular Diagnosis, Genetic Engineering and Biotechnology Institute, University of Sadat City, Sadat city, Egypt.

${ }^{7}$ Department of Molecular Biology, Genetic Engineering and Biotechnology Institute, University of Sadat City, Sadat city, Egypt.

Running Title: Vitamin-D Impact on rheumatoid arthritis patients

Corresponding Author:

Professor Dr. Mohamed Elshal

Current address: Molecular Biology Depatment,

Genetic Engineering and Biotechnology Institute,

University of Sadat City,

Sadat City, Egypt.

$\begin{array}{ll}\text { Email } & : \text { Mohamed.elshal@ gebri.usc.edu.eg } \\ \text { ORCID No. } & : \text { 0000-0001-8973-6847 } \\ \text { Researcher ID } & : \text { H-7953-2012 } \\ \text { Scopus ID } & : 6506130470\end{array}$

Key Words: Rheumatoid arthritis, vitamin D3, cardiovascular diseases, flow-mediated dilation, circulating endothelial cells, adhesion molecules, endothelial growth factor.

\section{ABSTRACT}

Background: Vitamin D is a steroid hormone that affects the expression of many genes and regulates a wide variety of cell types and organ systems, including the cardiovascular system. Patients affected by rheumatoid arthritis (RA) present with accelerated atherosclerosis and increased risk of cardiovascular disease (CVD). Aim: The aim is to evaluate the impact of vitamin-D intake on markers of vascular function in patients with RA. Methods: Forty RA with vitamin-D deficient patients were included and were supplemented with oral doses of cholecalciferol (50,000 IU) weekly 
for 8 weeks. Conventional rheumatoid measures such as DAS-28, RF, CRP and anti-MCV as well as measures of vascular functions flow-mediated dilatation (FMD) and circulating endothelial cells (CECs) and serum adhesion markers ICAM and VCAM were assessed at baseline and 8 weeks post-treatment. Forty healthy individuals were included as controls. Results: RA patients showed impaired FMD as compared with controls $(4.28 \%$ vs $10.10 \%, \mathrm{p}<0.05)$. Significant inverse relationships were detected between DAS-28 score and both vitamin D and FMD ( $\mathrm{r}=0.437 ; \mathrm{P}=0.001$ and $\mathrm{r}=0.315 ; \mathrm{P}=0.002$ respectively). Vitamin-D intake was associated with significant improvement in FMD and lower CECs numbers. Intervention also led to significant favorable effects on inflammatory (CRP and ESR), rheumatic (RF, anti-MCV) and on circulating adhesion molecules levels (ICAM and VCAM). Conclusion: The present data indicate that supplementing RA with VD3 significantly improves vascular functions as indicated by enhanced FMD through a mechanism that involves regulation of adhesion molecules and inflammatory mediators.

\section{INTRODUCTION}

Rheumatoid arthritis (RA) is a systemic chronic autoimmune inflammatory disorder that affects approximately 1 percent of the population worldwide ${ }^{1}$. It is characterized by variable autoreactivities immune cells and autoantibodies against immunoglobulin G, cartilage components, stress proteins, enzymes, nuclear proteins and citrullinated proteins causing inflammation of the lining of the joints, in a symmetric pattern ${ }^{2,3}$. Although primarily involves the joints, RA can have a significant impact on other organ systems specially the heart and vascular system ${ }^{4,5}$. In addition, numerous epidemiological investigations have revealed that risk of developing cardiovascular diseases (CVD) in RA patients RA is more than double that of the general population ${ }^{6,7}$.

Clinical and experimental data support that inflammatory responses that accompanied immune-mediated disorders cause activation of endothelium and overexpression of key adhesion molecules involved in the recruitment of leukocytes to the endothelium. Adherence of leukocytes to endothelial cells leads to disruption of the endothelial glycocalyx and to detachment of endothelial cells into the circulation ${ }^{8-10}$. Recently, circulating endothelial cells (CECs) have emerged as hallmarks of vascular dysfunction ${ }^{11,12}$. CECs are present in very small numbers in healthy individuals, whereas their number increases dramatically in diseases with vascular damage, such as CVD, sepsis, vasculitis, and autoimmune diseases ${ }^{13-18}$. Several adhesion molecules involved in this process including vascular cell adhesion molecule-1 (VCAM-1) and intracellular cell adhesion molecule-1 (ICAM-1) ${ }^{8}$. Leukocytes adhere to endothelium then transmigrate through it to the vascular and extravascular spaces that are central to endothelial dysfunction and the development of atherosclerotic plaques and vascular inflammatory disorders ${ }^{19,20}$. In contrast to 
healthy endothelium, dysfunctional endothelium loses its capacity of relaxation in response to mediators such as acetylcholine or to increased blood flow. Therefore, endothelial dysfunction could be detected by impaired flowmediated dilation (FMD) ${ }^{21,22}$. FMD has been suggested as a marker of the grade of atherosclerosis and may be used as a surrogate marker of cardiovascular outcomes ${ }^{23}$.

Many cardiovascular risk factors have been recognized. Among them, vitamin D (VD) deficiency [25(OH) D $<20 \mathrm{ng} / \mathrm{mL}$ ] is emerging as a novel one 24,25 . VD is a steroid hormone that is photosynthesized mainly by skin upon the exposure to sun light ${ }^{26}$. VD can also be supplemented through diet where gastrointestinal absorption takes it to blood circulation ${ }^{27,28}$. In addition to its well-defined role in bone and calcium metabolism, vitamin $\mathrm{D}$ has been identified as an vital factor in several physiological processes, including immunity, cellular growth, and cellular differentiation ${ }^{29}$. VD exerts these diverse physiological functions upon binding to its nuclear receptor (VDR), a ligand-responsive transcription factor that is ubiquitously expressed in a wide variety of cell types and organ systems, including the cardiovascular system ${ }^{30}$. Recent studies reported the expression of VDR on vascular endothelial cells and that its interaction with VD results in the expression of hundreds of gene targets which regulate vascular cell growth, migration, and differentiation; immune response modulation; cytokine expression; and inflammatory and fibrotic pathways, all of which play a crucial role, starting from the early stage of endothelial activation/dysfunction to the later stages of the plaque vulnerability and rupture ${ }^{31}$.

In Saudi Arabia, the current epidemiological data indicate that vitamin D deficiency is prevalent in more than $80 \%$ of Saudi population, and it might be related to lack of adequate exposure to sunlight and inadequate consumption of dairy products ${ }^{32}$. Deficiency of vitamin $\mathrm{D}$ has been acknowledged as an independent predictor of CVD in patients with RA ${ }^{33-35}$. In addition, several studies have suggested that vitamin D deficiency in RA may affect inflammatory responses and endothelial functions ${ }^{36-38}$. These reports suggest that maintaining normal serum vitamin D levels may protect against CVD in patients with RA. To test this suggestion, and due to the lack of clinical studies on the effects of Vitamin D supplementation, we designed the current study to assess the impact of vitamin D intake on inflammatory markers, vascular functions measures and circulating endothelial adhesion molecules.

\section{MATERIALS AND METHODS}

\section{Study Design}

The present randomized cross-sectional study was carried out during the period from September 2014 and July 2015. All the patients met the 2010 American College of Rheumatology/European League Against Rheumatism (EULAR) criteria for RA classification ${ }^{39}$. All procedures 
performed in the study were in accordance with the ethical standards of the institutional and/or national research committee and with the 1964 Helsinki Declaration and its later amendments or comparable ethical standards. All patients who participated in the present study signed an informed consent form per the Declaration of Helsinki (October 2008). The study included two groups of subjects: group A, consists of 50 patients with RA and group B, consists of 40 healthy sex- and age-matched controls. After initial clinical assessment, patients with serum vitamin $\mathrm{D}(25(\mathrm{OH}) \mathrm{D})<25 \mathrm{ng} / \mathrm{mL}$ were supplemented with oral cholecalciferol 50,000 IU per week for 8 weeks. Anthropometric data of the patients and healthy controls and clinical data were collected from the questionnaire designed for each group. The main clinical data that were collected are age, smoking, disease activity, disease duration, DAS-28 (disease activity score of 28 joints), ability of movement, vitamin D supplementations, dairy consumption, and sun's exposure. Due to incomplete follow-up data from the hospital and absence of patients at follow-ups, the final number in group A became 40 patients.

\section{Blood samples}

Blood samples were withdrawn into two Ethylenediaminetetraacetic acid (EDTA) tubes. Serum was separated from one tube by centrifugation at $1500 \mathrm{rpm}$ for 5 minutes. Serum samples were aliquoted in eppendorf tubes and were stored at $-80{ }^{\circ} \mathrm{C}$ until analysis. The other blood tube was mixed with 5ml of Hank's Balanced Salt Solution (HBSS), and slowly layered on top of Ficoll-Paque Premium solution (GE-Healthcare, USA) for leukocyte separation. The tubes were centrifuged at $1400 \mathrm{rpm}, 4^{\circ} \mathrm{C}$ with no break for 30 minutes. The developed buffy coat was then collected and washed twice in HBSS. Leukocytes were then stored in frozen nutrient media (23\% RPMI $1640+70 \%$ Fetal Bovine Serum + 7\% Dimethylsulfoxide DEMSO).

\section{Estimation of serum Vitamin D3}

Vitamin D3 levels were determined in the serum using 25 Hydroxy Vitamin D (25OHVD) ELISA kit (Cat. No. MBS722906, My BioSource, Inc. San Diego, CA, USA) according to the manufacturer's instructions.

\section{Determination of vascular function markers}

\section{a. FMD index assessments}

FMD is the most widely used non-invasive method to assess the endothelial function, reflecting the endothelial nitric oxide (NO) dependent vasodilation in response to occlusion-induced reactive hyperemia. FMD assessments were done using Philips iU22 high-end ultrasound machine at the Ultrasound Vascular Lab, King Abdulaziz University Hospital. This system is equipped with vascular software for two-dimensional (2D) 
imaging, color and spectral Doppler, an internal electrocardiogram (ECG) monitor and a high-frequency vascular transducer. A linear array transducer with a minimum frequency of $7 \mathrm{MHz}$, attached to a high-quality mainframe ultrasound system, was used to acquire images with sufficient resolution for subsequent analysis. Images of the brachial artery were obtained for subjects after they were positioned in supine with the arm in a comfortable position for imaging. The brachial artery was imaged above the antecubital fossa in the longitudinal plane. A segment with clear anterior and posterior intimal interfaces between the lumen and vessel wall was selected for continuous 2D gray scale imaging. Percent of FMD was calculated as follows: [(post deflation diameter - resting diameter) / resting diameter] X 100.

\section{b. CECs using Flow Cytometry (FCM)}

CECs were enumerated using Flow Cytometry (FCM) as described previously ${ }^{40}$. Briefly, stored BPMCs samples were thawed and washed before the addition of Anti-CD3 FITC (Cat. No. ab34275, Abcam, Cambridge, UK), CD146 [P1H12] Phycoerythrin (PE) (Cat. No. ab78488, Abcam, Cambridge, UK) and CD45 Allophycocyanin (APC) (Cat. No. ab28106, Abcam, Cambridge, UK) monoclonal antibodies antibodies. After incubation for $20 \mathrm{~min}$ in the dark, 5 ul of 7-Aminoactinomycin D (7-AAD) (Cat. No. ab142391, Abcam, Cambridge, UK) were added 5 minutes before analysis for exclusion of dead cells. Stained samples were then analyzed using Navios software on Gallios ${ }^{\mathrm{TM}}$ Flow Cytometer (Beckman Coulter, Inc., Miami, FL, USA). A sequential flow cytometry strategy was used for enumeration of CECs as illustrated in Figure 1.

\section{Determination of serum adhesion markers}

Adhesion molecules were determined in serum samples using ELISA kits for vascular cell adhesion molecule 1 (VCAM1, Cat. No. ab187393, Abcam, Cambridge, UK), intercellular adhesion molecule 1 (ICAM1, Cat. No. ab187403, Abcam, Cambridge, UK), vascular endothelial growth factor (VEGF, Cat. No. ab100662, Abcam, Cambridge, UK), and vascular endothelial growth factor receptor 1 (VEGFR1, Cat. No. ab119567, Abcam, Cambridge, UK) according to the manufacturer's instructions.

\section{Statistical Analysis}

Statistical analysis was performed using SPSS software (version 20; SPSS Inc., Chicago, IL, USA). Values are expressed as mean \pm standard deviation. The Student's t-test was used to assess differences in tested parameters between RA patients and the control group. Pearson's Chi-square test was used to evaluate correlations between parameters. A level of 0.05 (two-sided) was chosen to indicate statistical significance. 


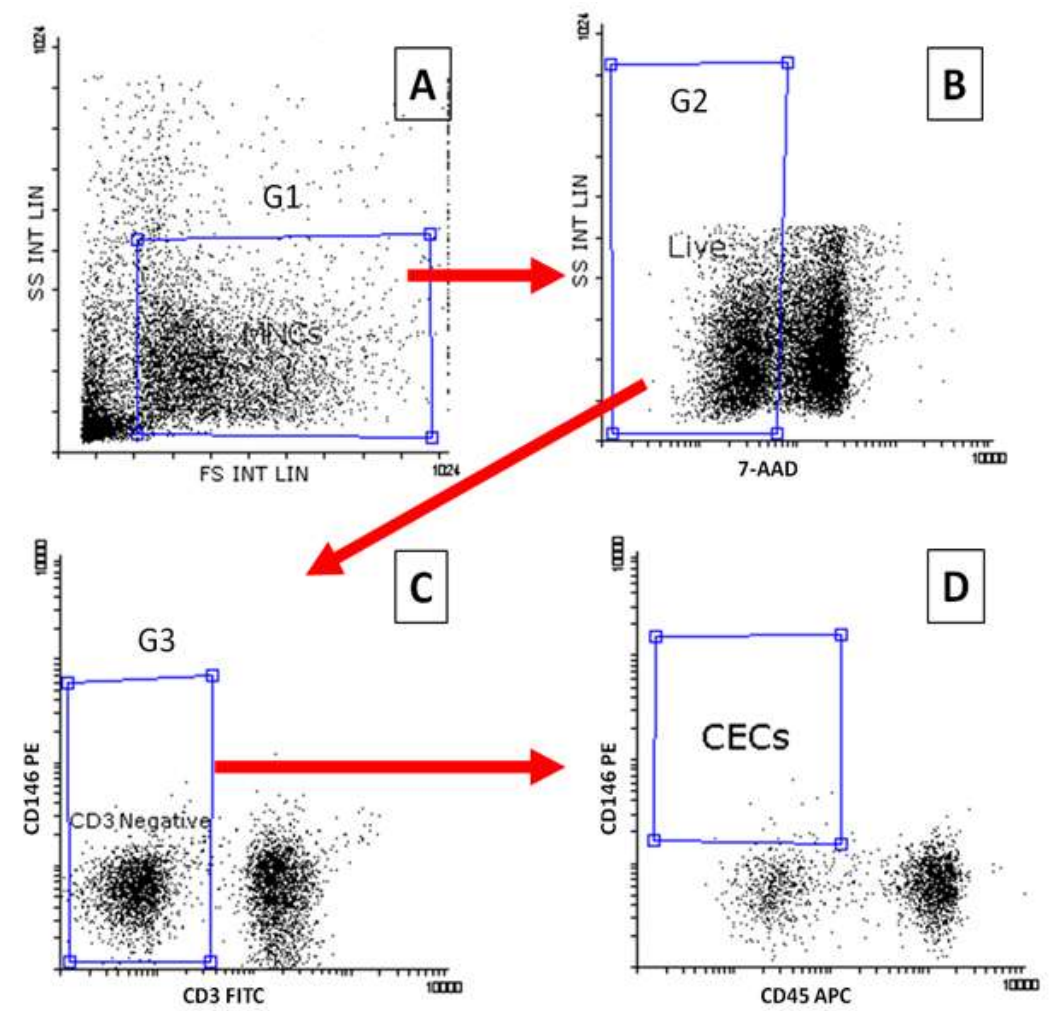

Figure 1: Sequential flow cytometry strategy for enumeration of CECs. CECs are defined as CD45 - /CD3 - /CD146 + using CD3-FITC, CD146-PE, CD45APC conjugated antibodies. CECs: (A) Forward (FSC) and side scatter (SSC) plot of white blood cells and gating region G1 to include all mononuclear cell events while excluding platelets, dead cells, and microparticles. (B) Live cells were selected as 7AAD- events in region G2 on an Intensity 7AAD versus Intensity SSC plot gated on G1. (C) CD3 negative events were selected on cellular events from gated region G2. (D) CD146+CD45- CECs were selected in a plot gated on live single CD3- cells from G3.

\section{RESULTS}

Forty patients had completed the follow-up visit at 8 weeks after treatment. The demographic data of the patients and healthy controls were collected from the questionnaire designed for the current study and were presented. The age range was 17-86 years. Eleven out of the 51 RA patients have been excluded from the study due to incomplete follow-up data. Disease duration ranged from 6 months to 12 years with mean of $89.62 \pm 83.88$ months. Three $(7.5 \%)$ RA patients were smokers and 3 other patients have significant movement difficulties. No significant difference in dairy consumption or sun exposure between patients and controls. All patients have received corticosteroids previously and more than $35 \%$ of 
patients were under treatment with Methotrexate and Plaquenil (DMARDs; Disease-modifying antirheumatic drugs).

Figure 2 shows that RA patients had significantly higher DAS-28 before treatment compared with controls $(\mathrm{P}<0.001)$. After treatment, mean DAS-28 value was lower in comparison to baseline values, however the difference was not statistically significant $(\mathrm{P}>0.05)$. Demonstrates the biochemical measurements and inflammatory markers of the RA patients at baseline and post-treatment with oral VD3 as compared to the reference group. At baseline, RA patients showed significantly $(\mathrm{P}<0.05)$ lower serum total vitamin D and serum VD3 concentrations compared with controls Both at $\mathrm{P}<0.05$ ). Whereas after treatment with oral 50,000 IU vitamin D3 per week for 8 weeks; RA patients showed significantly higher levels of total vitamin $\mathrm{D}$ in comparison to their baseline values and to that of controls ( $p<0.05 ; p<0.001$ respectively). After treatment, levels of serum vitamin D3 were slightly increased ( $p>0.05)$ compared with RA before treatment. The inflammatory markers CRP and ESR were found significantly lower in patients received VD3 than their baseline levels. Treatment with VD3 also reduced the rheumatic markers RF and Anti-MCV compared than that measured at baseline.

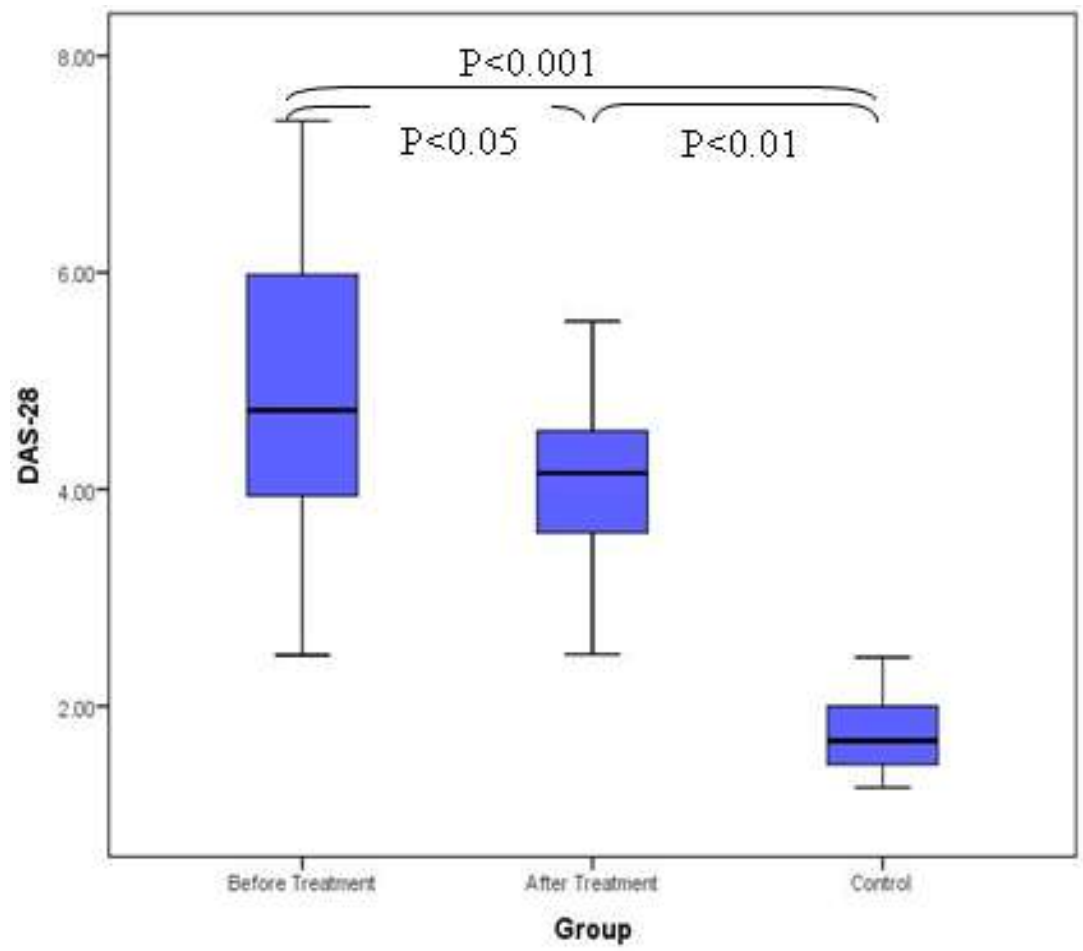

Figure 2: Mean DAS-28 levels in RA patients before and after vitamin D treatment in comparison to controls. 
FMD of the brachial artery is an accepted procedure for noninvasive assessment of systemic endothelial function. The mean value of FMD in controls was $15.13 \pm 11.32 \%$ (median, 8.9\%; IQR, 4.0-8.0\%; range, 7.87-21.9\%) (Figure 3A). Baseline FMD was significantly lower in RA group than in controls $(6.33 \pm 6.58$ vs $15.13 \pm 11.32 \%, \mathrm{p}<0.01)$. Post Treatment, RA group showed significant improvement in FMD compared with baseline measurements $(6.33 \pm 6.58$ vs $12.92 \pm 7.18 \mathrm{~mm}$, $\mathrm{p}<0.05)$.

CECs were enumerated before and post treatment using flow cytometry as illustrated in Figure 1. Baseline CECs numbers were found significantly higher in RA group $(\mathrm{p}<0.001)$. CECs numbers also significantly reduced post vitamin D3 treatment compared with pretreatment numbers. However, post-treatment CECs numbers were still significantly higher than in controls (Figure 3B).
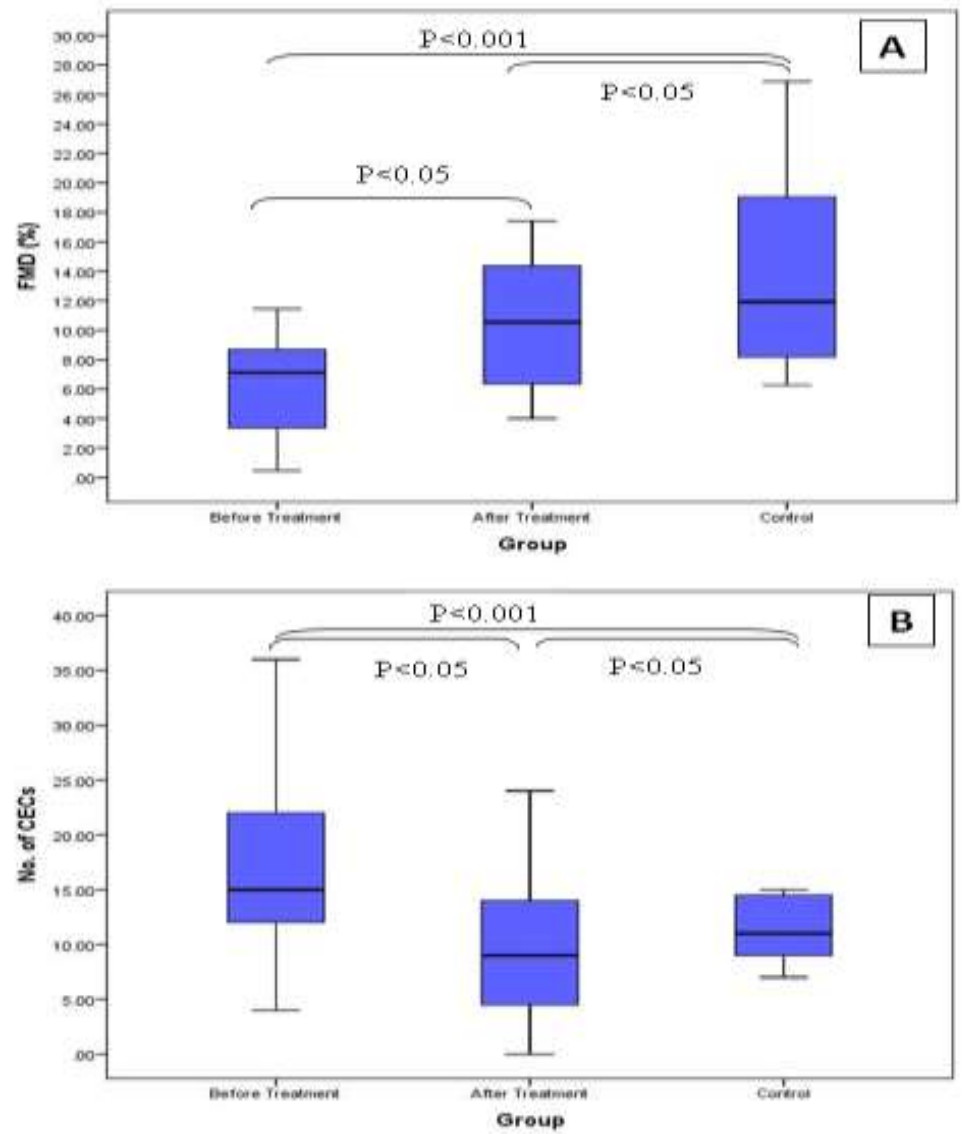

Figure 3: Endothelial biomarkers FMD\% (A) and number of CECs as measured by flow cytometry $(B)$ in RA patients in Comparisons to controls. 
The concentrations of serum endothelial growth factors and adhesion molecules of the RA patients in comparisons controls are demonstrated. Serum VEGF showed significant increase $(\mathrm{P}<0.01)$ at baseline and then decreased significantly $(\mathrm{P}<0.05)$ after 8 weeks of treatment. The soluble receptors of VEGF type 1 (sVEGFR-1) also significantly $(\mathrm{P}<0.05)$ decreased after treatment. Serum concentrations of adhesion molecules VCAM1 and ICAM1 also showed significant increase at baseline (both at $\mathrm{p}<0.01$ ) in comparison to controls. After treatment a significant decrease were only recorded in VCAM1 $(\mathrm{P}<0.01)$ compared with their baseline values. In case of ICAM1, our patients did not show significant decrease post-treatment in comparison to baseline values.

Pearson correlations analyses revealed a significant negative correlation between DAS-28 with serum vitamin D3 $(r=0.437 ; \mathrm{P}=0.001)$ and with $\mathrm{FMD} \%(\mathrm{r}=0.315 ; \mathrm{P}=0.002)$, while no correlation was found between DAS-28 with CECs (Figure 4A, B).
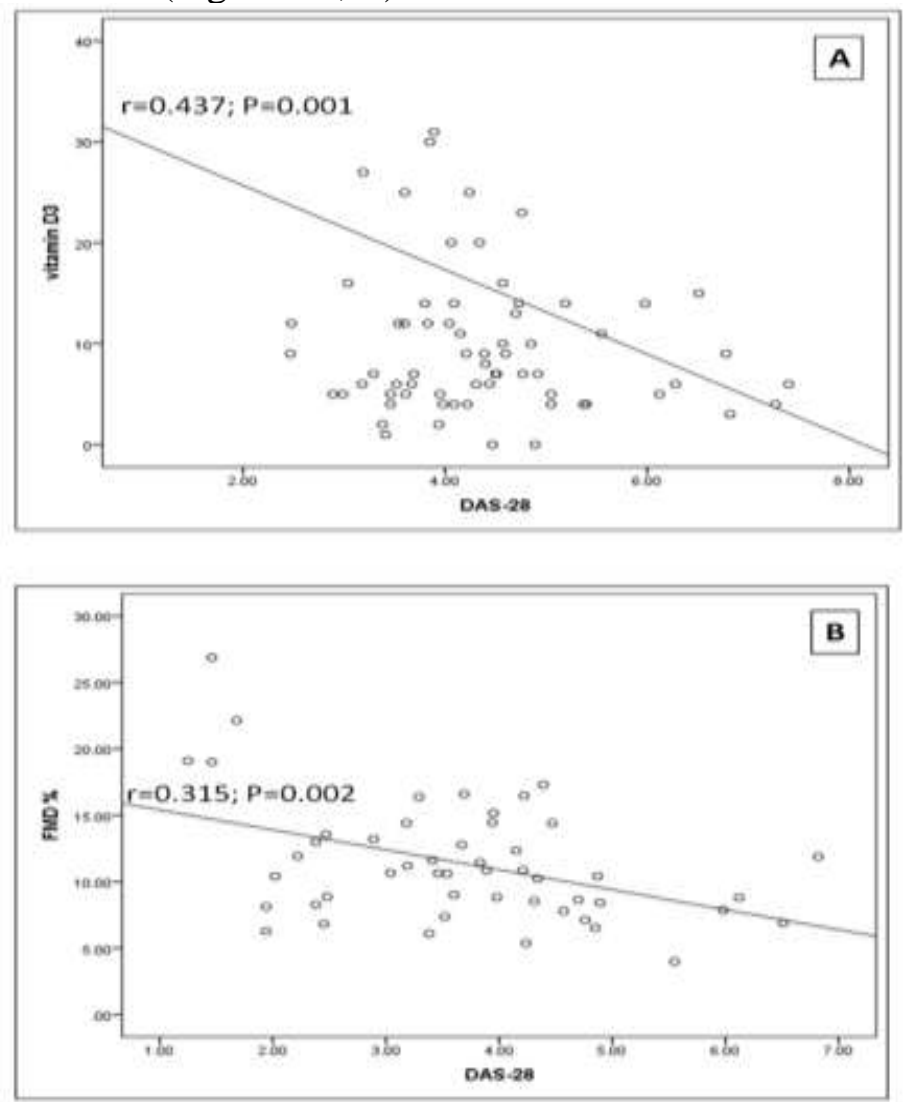

Figure 4: Correlations of disease activity score (DAS-28) with (A) levels of serum Vitamin D3 and (B) percent of flow mediated dilation 


\section{DISCUSSION}

The pathogenesis of the chronic inflammation related rheumatic autoimmune diseases diversified greatly based on the area, the way of living, and social position suggesting that genetic and environmental factors play an essential role in occurrence and advancement of rheumatic diseases ${ }^{41}$. In Saudi Arabia, the current epidemiological data indicate that overall Vitamin D deficiency is $63.5 \%$ (95\% CI: 53.3, 73.7), and it might be related to lack of adequate exposure to sunlight and possibly inadequate consumption of dairy products ${ }^{42}$. Several researchers have confirmed a greater occurrence of vitamin D deficiency in RA patients in comparison to healthy people ${ }^{33}$. Studies also show that prevalence of vitamin D deficiency in RA and that there is an association with disease activity and cardiovascular risk factors ${ }^{33-}$ 35 . Therefore, it has been proposed by several research groups that vitamin D and its analogs not only can ameliorate autoimmune diseases, but also could be utilized in the management of associated vascular disorders ${ }^{43-45}$. In the current study, the total vitamin D was measured before and after supplementation of RA patients with VD3. Post treatment with $50000 \mathrm{U}$ of oral VD3 per week for 2 months, RA patients showed significant increase in total vitamin D levels (VD2 plus VD3) compared with its levels before the treatment.

Autoantibodies are frequent and characteristic aspect of rheumatic autoimmune diseases. While the greater part of autoantibodies do not appear to perform a significant pathogenetic function in these disorders, some of them have found highly beneficial as diagnostic methods and signs of disease activity. Our study revealed that the RF was significantly higher in RA group compared with healthy group. Supplementation with vitamin D significantly reduced RF quantities in both categories, suggesting Vitamin D ability to ameliorate the increase in RF associated with RA. Mutated citrullinated vimentin MCV autoantibodies are an indication of preceding damage to the joints and extreme advancement of the disease ${ }^{46}$. The antiMCV ELISA locates autoantibodies against MCV. It is a powerful and effective serological analysis for rheumatoid arthritis as it detects the disease at earliest stage, even in patients who has been recognized as negative for $\mathrm{RF}$, and to some extent even prior to the appearance of certain clinical signs 47. Based on our data, there was a significant reduction in MCV levels after treatment with vitamin D3.

The level of disease activity in RA is frequently assessed with the Disease Activity Score of 28 Joints (DAS-28). Higher disease activity has been also involved with increased death rate, and experiments have shown that death rate is decreased by intense treatments for RA ${ }^{48}$. Song et al. review the reverse relationship between disease activity in RA patients and levels of serum vitamin D ${ }^{49}$. The current study is in line with Song's 
findings that supplementation of RA patients with vitamin D3 reduces the levels of DAS-28.

The studies in recent years revealed that vitamin D deficiency could influence endothelial performance ${ }^{35}$. FMD of brachial arteries is a validated and useful biomarker of endothelial functionality ${ }^{22,23}$. Harris and colleagues noticed that vitamin D3 supplements could enhance FMD in comparison to placebo users ${ }^{50}$. Additionally, Malik, Giri ${ }^{51}$ reported that there were significant increases in \%FMD in patients of myocardial infarction after vitamin D supplementation. In line with these studies, our data show enhanced FMD after vitamin D supplementation. These finding may suggest that vitamin D3 supplementations may improve endothelial performance.

Damage to endothelium has been associated with CVD morbidity and mortality in young patients with RA ${ }^{34,52}$. Endothelial damage correspond with disease development and estimates $\mathrm{CV}$ activities in the normal population ${ }^{53}$. CECs $\left(\mathrm{CD} 45^{-} \mathrm{CD} 146^{+}\right)$are angiogenic cells that are truly uncommon in normal individual peripheral blood and seem to be elevated in numbers in the peripheral circulation as a consequence of vascular damage or in response to vasculogenic stimulating factors $12,22,54$ 55 . Several researches suggest that vitamin D may influence ECs indirectly through regulating inflammatory mediators on the blood vessels ${ }^{34,56}$. In agreement with these data, the present study demonstrates that administration of VD3 was associated with significant decrease in CECs, and that decrease was concomitant with significant decrease in the inflammatory disease activity index DAS-28 and the other conventional inflammatory markers ESR, CRP and anti-MCV. In addition, it has been reported that vitamin $\mathrm{D}$ might reduce $\mathrm{CVD}$ and cardiovascular risk by regulating the production of VEGF and protecting the endothelial cells from oxidative stress through autophagic and survival pathways ${ }^{56,57}$. It has been reported that increased levels of VEGF may result in alterations of endothelial functions, which may subsequently trigger the valvular remodelling or even damage of heart valves that may leads to rheumatic heart diseases 57 . Also, it has been reported that VEGF and its receptor VEGFR-1 levels are positively correlated with disease activity in RA patients ${ }^{58-60}$. In agreement with these studies, we have observed that the levels of VEGF were significantly reduced in patients after supplementation with vitamin D3, confirming the role of VD3 in regulating VEGF production. The integrins or the adhesion molecules (ICAM1 and VCAM1) also appeared to have important roles in development of rheumatic heart disease as it were found associated with valvular lesion, cardiac muscle cell death and heart failure ${ }^{61}$. ICAM and VCAM adhesion molecules belong to a subgroup of Ig-like superfamily gene that is secreted from the endothelium. The secretion of these molecules was found positively associated with endothelial cell damage and endothelial activation and cause 
adhesion of leukocytes to the vascular membrane and escalation of the atherosclerotic process ${ }^{9,61}$. In the present study the concentrations of serum integrins were found significantly higher in RA patients at baseline. However, their concentrations were reduced dramatically post-treatment with oral VD3. Our results are comparable to that of Naeini, Moeinzadeh ${ }^{62}$ who found that administration of 50,000 IU Vitamin D orally per week for 8 weeks in ESRD patients reduces serum levels of ICAM and VCAM which might improve the vascular condition of these patients. In summary, despite the limitations of small number of patients in this study, the preliminary results demonstrated that treatment of patients with RA with vitamin D 50,000 IU per week improved the endothelial functions as indicated by enhanced FMD and lowered numbers of CECs, VEGF and the levels of adhesion molecules ICAM-1 and VCAM-1.

\section{CONFLICT OF INTERESTS}

None.

Ethics Approval

Arabia.

King Abdulaziz University Research Ethics Board, Jeddah, Saudi

Informed consent:

Informed consent was obtained from all individual participants included in the study.

\section{Acknowledgments}

The authors would like to acknowledge the King Abdulaziz City for Science and Technology KACST for funding this study.

\section{REFERNCES}

1. van der Woude, D. and van A.H.M. der Helm-van Mil (2018): Update on the epidemiology, risk factors, and disease outcomes of rheumatoid arthritis. Best Pract Res Clin Rheumatol; 32: 174-187.

2. Yap, H.Y. ; S.Z. Tee ; M.M. Wong and et al.(2018): Pathogenic Role of Immune Cells in Rheumatoid Arthritis: Implications in Clinical Treatment and Biomarker Development. Cells; 7 2018/10/12. DOI: 10.3390/cells7100161.

3. Alivernini, S. ; B. Tolusso ; G. Ferraccioli and et al.(2018) Driving chronicity in rheumatoid arthritis: perpetuating role of myeloid cells. Clin Exp Immunol; 193: 13-23. 2018/01/10. DOI: 10.1111/cei.13098.

4. Urman, A. ; N.Taklalsingh ; C. Sorrento and et al.(2018): Inflammation beyond the Joints: Rheumatoid Arthritis and Cardiovascular Disease. Scifed J Cardiol; 2 2019/01/05. 
5. Amigues, I. ; A. Tugcu ; C. Russo and et al.(2019): Myocardial Inflammation, Measured Using 18-Fluorodeoxyglucose Positron Emission Tomography With Computed Tomography, Is Associated With Disease Activity in Rheumatoid Arthritis. Arthritis Rheumatol; 71: 496-506. 2018/11/09. DOI: 10.1002/art.40771.

6. Blum, A. and M. Adawi (2019): Rheumatoid arthritis (RA) and cardiovascular disease. Autoimmun Rev ., 2019/05/07. DOI: 10.1016/j.autrev.2019.05.005.

7. Agca, R. ; L. Hopman ; K.C.J.Laan and et al.(2019): Cardiovascular Event Risk in Rheumatoid Arthritis is Higher than in Type 2 Diabetes: a 15 Year Longitudinal Study. $J$ Rheumatol ,2019/05/17. DOI: 10.3899/jrheum.180726.

8. Moroni, G. ; N. Del Papa ; L.M. Moronetti and et al.(2005): Increased levels of circulating endothelial cells in chronic periaortitis as a marker of active disease. Kidney Int; 68: 562568. 2005/07/15. DOI: 10.1111/j.1523-1755.2005.00434.x.

9. Kluz, J. ; W. Kopec ; U. Jakobsche-Policht and et al. (2009): Circulating endothelial cells, endothelial apoptosis and soluble markers of endothelial dysfunction in patients with systemic lupus erythematosus-related vasculitis. Int Angiol; 28: 192-201. 2009/06/10.

10. Dane, M. ; B. van den Berg and T. Rabelink (2014): The endothelial glycocalyx: scratching the surface for cardiovascular disease in kidney failure. Atherosclerosis; 235: 56-57. /05/13. DOI: 10.1016/j.atherosclerosis.2014.04.005.

11. Totoson, P. ; K. Maguin-Gate ; M. Nappey and et al.(2016): Endothelial Dysfunction in Rheumatoid Arthritis: Mechanistic Insights and Correlation with Circulating Markers of Systemic Inflammation. PLoS One; 11: e0146744. 2016/01/14. DOI: 10.1371/journal.pone.0146744.

12. Farinacci, M. ; T. Krahn ; W. Dinh and et al.(2019): Circulating endothelial cells as biomarker for cardiovascular diseases. Res Pract Thromb Haemost; 3: 49-58. 2019/01/19. DOI: $10.1002 / \mathrm{rth} 2.12158$.

13. Erdbruegger, U. ; M. Haubitz and A.Woywodt (2006): Circulating endothelial cells: a novel marker of endothelial damage. Clin Chim Acta 2006; 373: 17-26. 2006/07/14. DOI: 10.1016/j.cca.2006.05.016. 
14. Budzyn, M. ; B. Gryszczynka ; M. Boruczkowski and et al. (2019): The endothelial status reflected by circulating endothelial cells, circulating endothelial progenitor cells and soluble thrombomodulin in patients with mild and resistant hypertension. Vascul Pharmacol; 113: 77-85. 2018/12/28. DOI: 10.1016/j.vph.2018.12.005.

15. Moussa, M.D. ; C. Santonocito ; D. Fagnoul and et al. (2014): Evaluation of endothelial damage in sepsis-related ARDS using circulating endothelial cells. Intensive Care Med; 41: 231-238. 2014/12/17. DOI: 10.1007/s00134-014-3589-9.

16. Milardi, D. ; G. Grande ; A. Giampietro and et al.(2012): Circulating endothelial cells as marker of endothelial damage in male hypogonadism. J Androl; 33: 1291-1297. 2012/06/16. DOI: $10.2164 /$ jandrol.112.016600.

17. Strijbos, M.H. ; P.P.Landburg ; E. Nur and et al.(2009): Circulating endothelial cells: a potential parameter of organ damage in sickle cell anemia? Blood Cells Mol Dis; 43: 63-67. 2009/04/10. DOI: 10.1016/j.bcmd.2009.02.007.

18. Boos, C.J. ; G.Y. Lip and A.D. Blann (2006): Circulating endothelial cells in cardiovascular disease. $\mathrm{J} \mathrm{Am} \mathrm{Coll} \mathrm{Cardiol;}$ 48: 1538-1547. 2006/10/19. DOI: 10.1016/j.jacc.2006.02.078.

19. Issekutz, A.C. (1998): Adhesion molecules mediating neutrophil migration to arthritis in vivo and across endothelium and connective tissue barriers in vitro. Inflamm Res; 47 Suppl 3: S123-132. 1998/11/27.

20. Weber, C. ; L. Fraemohs and E. Dejana (2007): The role of junctional adhesion molecules in vascular inflammation. Nat Rev Immunol; 7: 467-477. 2007/05/26. DOI: 10.1038/nri2096.

21. Lee, K.W. ; A.D. Blann and G.Y. Lip (2006): Inter-relationships of indices of endothelial damage/dysfunction [circulating endothelial cells, von Willebrand factor and flow-mediated dilatation] to tissue factor and interleukin-6 in acute coronary syndromes. Int J Cardiol; 111: 302-308. 2005/12/06. DOI: 10.1016/j.ijcard.2005.10.014.

22. Chong, A.Y. ; A.D. Blann ; J. Patel and et al.(2004): Endothelial dysfunction and damage in congestive heart failure: relation of flow-mediated dilation to circulating endothelial cells, plasma indexes of endothelial damage, and brain natriuretic peptide. 
Egypt. J. of Appl. Sci., 35 (11) 2020

Circulation; 110: 1794-1798. 2004/09/15. DOI: 10.1161/01.CIR.0000143073.60937.50.

23. Maruhashi, T. ; J. Soga ; N. Fujimura and et al.(2013): Relationship between flow-mediated vasodilation and cardiovascular risk factors in a large community-based study. Heart; 99: 1837-1842. 2013/10/25. DOI: 10.1136/heartjnl2013-304739.

24. Chen, F.H. ; T. Liu ; L. Xu and et al.(2018): Association of Serum Vitamin D Level and Carotid Atherosclerosis: A Systematic Review and Meta-analysis. J Ultrasound Med; 37: 1293-1303. 2017/11/25. DOI: 10.1002/jum.14494.

25. Karakas, M. ; B. Thorand ; A. Zierer and et al.(2013): Low levels of serum 25-hydroxyvitamin D are associated with increased risk of myocardial infarction, especially in women: results from the MONICA/KORA Augsburg case-cohort study. The Journal of Clinical Endocrinology \& Metabolism; 98: 272-280.

26. Perez-Lopez, F.R. (2007):Vitamin D: the secosteroid hormone and human reproduction. Gynecol Endocrinol; 23: 13-24. 2007/05/09.

27. Brouwer-Brolsma, E.M. ; H.A. Bischoff-Ferrari ; R. Bouillon and et al.(2013): Vitamin D: do we get enough? A discussion between vitamin $\mathrm{D}$ experts in order to make a step towards the harmonisation of dietary reference intakes for vitamin D across Europe. Osteoporos Int; 24: 1567-1577. 2012/12/12. DOI: 10.1007/s00198-012-2231-3.

28. Wolpowitz, D. and B.A. Gilchrest (2006): The vitamin D questions: how much do you need and how should you get it? $J$ Am Acad Dermatol; 54: 301-317. 2006/01/31. DOI: 10.1016/j.jaad.2005.11.1057.

29. DeLuca, H.F. (2004): Overview of general physiologic features and functions of vitamin D. Am J Clin Nutr; 80: 1689S-1696S. 2004/12/09. DOI: 10.1093/ajcn/80.6.1689S.

30. Wu-Wong, J.R.(2007): The potential for vitamin D receptor activation in cardiovascular research. Expert Opin Investig Drugs; 16: 407411. 2007/03/21. DOI: 10.1517/13543784.16.4.407.

31. Bozic, M. ; A. Alvarez ; C. de Pablo and et al.(2015): Impaired Vitamin D Signaling in Endothelial Cell Leads to an Enhanced Leukocyte-Endothelium Interplay: Implications for Atherosclerosis Development. PLoS One; 10: e0136863. 2015/09/01. DOI: 10.1371/journal.pone.0136863. 
32. Al-Daghri, N.M. (2018): Vitamin D in Saudi Arabia: Prevalence, distribution and disease associations. J Steroid Biochem Mol Biol; 175: 102-107.

33. Cecchetti, S. ; Z. Tatar ; P. Galan and et al.(2016): Prevalence of vitamin D deficiency in rheumatoid arthritis and association with disease activity and cardiovascular risk factors: data from the COMEDRA study. Clin Exp Rheumatol; 34: 984-990.

34. Lo Gullo, A. ; J. Rodriguez-Carrio ; C.O. Aragona and et al.(2018): Subclinical impairment of myocardial and endothelial functionality in very early psoriatic and rheumatoid arthritis patients: Association with vitamin D and inflammation. Atherosclerosis; 271: 214-222. 2018/03/11. DOI: 10.1016/j.atherosclerosis.2018.03.004.

35. Caraba, A. ; V. Crisan ; I. Romosan and et al.(2017): Vitamin D Status, Disease Activity, and Endothelial Dysfunction in Early Rheumatoid Arthritis Patients. Dis Markers; 2017: 5241012. 2017/12/05. DOI: 10.1155/2017/5241012.

36. Lo Gullo, A. ; G. Mandraffino ; G. Bagnato and et al. (2015): Vitamin D Status in Rheumatoid Arthritis: Inflammation, Arterial Stiffness and Circulating Progenitor Cell Number. PLoS One; 10: e0134602. 2015/08/05. DOI: 10.1371/journal.pone.0134602.

37. Delgado-Frias, E. ; R. Lopez-Mejias ; F. Genre and et al.(2015): Relationship between endothelial dysfunction and osteoprotegerin, vitamin D, and bone mineral density in patients with rheumatoid arthritis. Clin Exp Rheumatol; 33: 241-249. 2015/03/24.

38. Ranganathan, P. ; S. Khalatbari ; S. Yalavarthi and et al.(2013): Vitamin D deficiency, interleukin 17, and vascular function in rheumatoid arthritis. J Rheumatol; 40: 1529-1534. 2013/07/03. DOI: 10.3899/jrheum.130012.

39. Aletaha, D. ; T. Neogi ; A.J. Silman and et al. (2010): Rheumatoid arthritis classification criteria: an American College of Rheumatology/European League Against Rheumatism collaborative initiative. Arthritis Rheum; 62: 2569-2581. 2010/09/28. DOI: 10.1002/art.27584.

40. Elshal, M. ; A. Abdelaziz ; A. Abbas and et al. (2009): Quantification of circulating endothelial cells in peripheral blood of systemic lupus erythematosus patients: a simple and reproducible method of assessing endothelial injury and repair. 
Nephrol Dial Transplant; 24: 1495-1499. 2008/11/29. DOI: 10.1093/ndt/gfn650.

41. Sparks, J.A. and K.H. Costenbader (2014): Genetics, environment, and gene-environment interactions in the development of systemic rheumatic diseases. Rheum Dis Clin North Am; 40: 637-657. 2014/12/02. DOI: 10.1016/j.rdc.2014.07.005.

42. Al-Alyani, H. ; H.A. Al-Turki ; O.N. Al-Essa and et al. (2018): Vitamin D deficiency in Saudi Arabians: A reality or simply hype: A meta-analysis (2008-2015). J Family Community Med; 25: 1-4. 2018/02/02. DOI: 10.4103/jfcm.JFCM_73_17.

43. Kheiri, B. ; A. Abdalla ; M. Osman and et al.(2018): Vitamin D deficiency and risk of cardiovascular diseases: a narrative review. Clin Hypertens; 24: 9. 2018/07/07. DOI: 10.1186/s40885-0180094-4.

44. Antico, A. ; M. Tampoia ; R. Tozzoli and et al.(2012): Can supplementation with vitamin $\mathrm{D}$ reduce the risk or modify the course of autoimmune diseases? A systematic review of the literature. Autoimmun Rev; 12: 127-136. 2012/07/11. DOI: 10.1016/j.autrev.2012.07.007.

45. Franco, A.S. ; T.Q. Freitas ; W.M. Bernardo and et al.(2017): Vitamin D supplementation and disease activity in patients with immune-mediated rheumatic diseases: A systematic review and meta-analysis. Medicine (Baltimore); 96: e7024. 2017/06/08. DOI: 10.1097/MD.0000000000007024.

46. Innala, L. ; H. Kokkonen ; C. Eriksson and et al.(2008): Antibodies against mutated citrullinated vimentin are a better predictor of disease activity at 24 months in early rheumatoid arthritis than antibodies against cyclic citrullinated peptides. $J$ Rheumatol; 35: 1002-1008. 2008/04/10.

47. Dejaco, C. ; W. Klotz ; H. Larcher and et al.(2006): Diagnostic value of antibodies against a modified citrullinated vimentin in rheumatoid arthritis. Arthritis Res Ther; 8: R119. 2006/07/25. DOI: $10.1186 / \mathrm{ar} 2008$.

48. Listing, J. ; J. Kekow ; B. Manger and et al. (2015):Mortality in rheumatoid arthritis: the impact of disease activity, treatment with glucocorticoids, TNFalpha inhibitors and rituximab. Ann Rheum Dis; 74: 415-421. 2013/12/03. DOI: 10.1136/annrheumdis-2013-204021. 
49. Song, G.G. ; S.C. Bae and Y.H. Lee (2012): Association between vitamin $\mathrm{D}$ intake and the risk of rheumatoid arthritis: a metaanalysis. Clinical rheumatology; 31: 1733-1739.

50. Harris, S.S. ; A.G.Pittas and N.J.Palermo (2012): A randomized, placebo-controlled trial of vitamin D supplementation to improve glycaemia in overweight and obese African Americans. Diabetes Obes Metab; 14: 789-794. 2012/04/11. DOI: 10.1111/j.1463-1326.2012.01605.x.

51. Malik, S. ; S. Giri ; S.V. Madhu and et al. (2016):Relationship of levels of Vitamin D with flow-mediated dilatation of brachial artery in patients of myocardial infarction and healthy control: A case-control study. Indian J Endocrinol Metab; 20: 684-689. 2016/10/13. DOI: $10.4103 / 2230-8210.190558$.

52. Khan, F.(2010): Assessment of endothelial function as a marker of cardiovascular risk in patients with rheumatoid arthritis. Int $J$ Rheum Dis 2010; 13: 189-195. 2010/08/14. DOI: 10.1111/j.1756-185X.2010.01480.x.

53. Boos, C.J. ; A.D. Blann and G.Y. Lip (2007): Assessment of endothelial damage/dysfunction: a focus on circulating endothelial cells. Methods Mol Med; 139: 211-224. 2008/02/22.

54. Hill, J.M. ; G. Zalos ; J.P. Halcox and et al. (2003):Circulating endothelial progenitor cells, vascular function, and cardiovascular risk. $N$ Engl J Med; 348: 593-600. 2003/02/14. DOI: $10.1056 /$ NEJMoa022287.

55. Erdbruegger, U. ; A. Dhaygude ; M. Haubitz and et al.(2010): Circulating endothelial cells: markers and mediators of vascular damage. Curr Stem Cell Res Ther; 5: 294-302. 2010/06/10.

56. Uberti, F. ; D. Lattuada ; V. Morsanuto and et al.(2014): Vitamin $\mathrm{D}$ protects human endothelial cells from oxidative stress through the autophagic and survival pathways. $J$ Clin Endocrinol Metab; 99: 1367-1374. 2013/11/29. DOI: 10.1210/jc.2013-2103.

57. Sarkar, S. ; S. Chopra ; M.K. Rohit and et al.(2016): Vitamin D regulates the production of vascular endothelial growth factor: A triggering cause in the pathogenesis of rheumatic heart disease? Med Hypotheses; 95: 62-66. 2016/10/04. DOI: 10.1016/j.mehy.2016.09.001.

58. Ozgonenel, L. ; E. Cetin ; S. Tutun and et al. (2010); The relation of serum vascular endothelial growth factor level with disease 
duration and activity in patients with rheumatoid arthritis. Clin Rheumatol; 29: 473-477. 2010/01/14. DOI: 10.1007/s10067009-1343-4.

59. Sone, H. ; M. Sakauchi ; A. Takahashi and et al.(2001): Elevated levels of vascular endothelial growth factor in the sera of patients with rheumatoid arthritis correlation with disease activity. Life Sci; 69: 1861-1869. 2001/11/06.

60. Maeno, N. ; S. Takei ; H. Imanaka and et al.(1999): Increased circulating vascular endothelial growth factor is correlated with disease activity in polyarticular juvenile rheumatoid arthritis. $J$ Rheumatol; 26: 2244-2248. 1999/10/21.

61. Hafez, M. ; S. Yahia ; W. Eldars and et al.(2013): Prediction of residual valvular lesions in rheumatic heart disease: role of adhesion molecules. Pediatr Cardiol; 34: 583-590. 2012/09/19. DOI: 10.1007/s00246-012-0501-7.

62. Naeini, A.E. ; F. Moeinzadeh ; S. Vahdat and et al.(2017): The Effect of Vitamin D Administration on Intracellular Adhesion Molecule-1 and Vascular Cell Adhesion Molecule-1 Levels in Hemodialysis Patients: A Placebo-controlled, Double-blinded Clinical Trial. J Res Pharm Pract; 6: 16-20. 2017/03/24. DOI: 10.4103/2279-042X.200994.

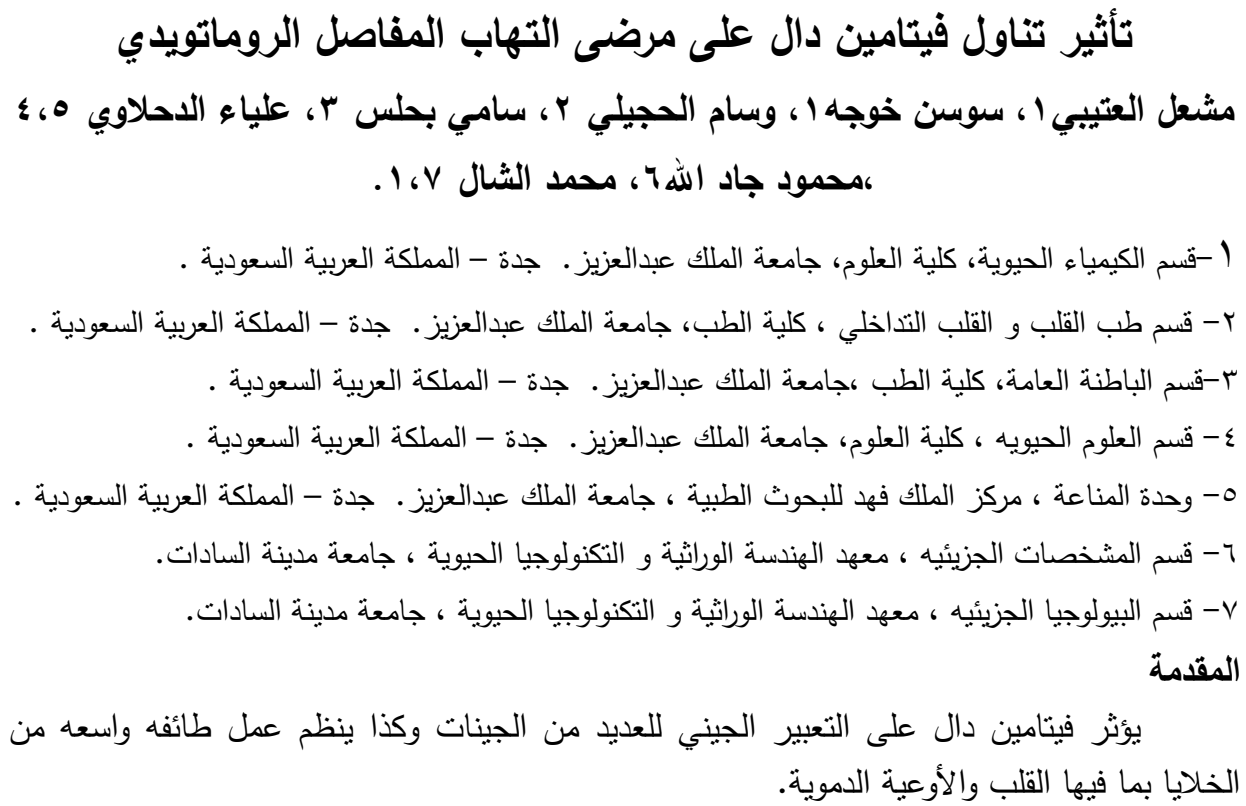


المرضي المصابون بالتهاب المفاصل الروماتويدي عادةً ما يعانون من تصلب الثرايين وخطر الإصابة بأمراض القلب والأوعية الدموية.

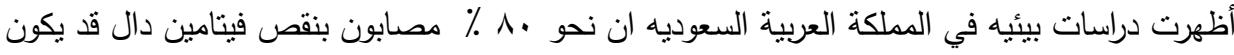
بسبب عدم التعرض للثمس او لقلة تتاول اطعمة ومنتجات تحتوي على فئل فيتامين دال. الهذف من الاراسة تقييم اثر تناول فيتامين دال علي وظائف الاوعيه الدمويه في مرضي الرومانويد. المرضي والطرق المستخدمة شملت الدراسة مجموعنين الأولى من .0 مريضًا بالروماتويد يعانون من نقص فيتامين دال مقارنة

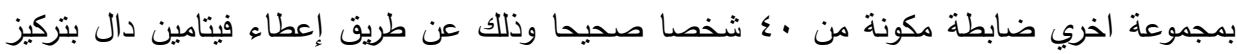

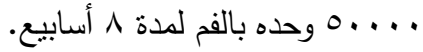

النتائج

أظهرت النتائج زيادة ملحوظة في عوامل النمو المبطنة للاوعية الدمويه وجزيئات الالتحام مقارنة بالمجمعة الضابطة وذلك عن طريق الية تحفز وتنظم عمل وسائط الالتهاب

الخلاصة

تتاول فيتامين دال في المرضي الدصابون بالتهاب الدفاصل الروماتويدي يؤدي الي تحسن ملحوظ في وظائف الأوعية الدموية وذلك عن طريق الية تحفز وتتظم عمل وسائط الالتهاب 